\title{
ANÁLISE DOS CONTEÚDOS DE FÍSICA NOS LIVROS DIDÁTICOS DE CIÊNCIAS DO NONO ANO DO ENSINO FUNDAMENTAL APROVADOS PELO PNLD 2017
}

\author{
Savana dos Anjos Freitas ${ }^{1}$ \\ Agostinho Serrano de Andrade Neto ${ }^{2}$
}

\begin{abstract}
RESUMO
Este trabalho teve como objetivo analisar e categorizar os 13 livros didáticos de Ciências do nono ano do Ensino Fundamental aprovados pelo PNLD 2017. Esta análise busca compreender como os estudantes são apresentados à Física no último ano do Ensino Fundamental e como os conteúdos da disciplina são distribuídos em um livro. As obras analisadas foram avaliadas com base em quatro categorias utilizadas na literatura e na legislação vigente no país. A análise e a categorização dos livros evidenciaram aspectos positivos, tais como o fato de que a quantidade dos conteúdos de Física é semelhante à quantidade de conteúdos de Química. Como aspectos negativos, alguns conteúdos de Física não são abordados ou sequer são mencionados, enquanto outros são discutidos exageradamente, em especial a Cinemática. Como é no Ensino Fundamental que a Física é apresentada e a relação do aluno com a disciplina pode ser forjada, acreditamos que é preciso adotar um cuidado especial na escolha de um livro didático. Além disso, observa-se que a quantidade de conteúdos de Física Mecânica nos anos finais do Ensino Fundamental é muito grande, e que todos os conteúdos da Física, incluindo a Física Moderna e Contemporânea, deveriam ser abordados.
\end{abstract}

Palavras-chave: Livros didáticos. Ensino Fundamental. Ensino de Física.

ANALYSIS OF THE PHYSICS CONTENTES IN THE SCIENCE DIDACTIC BOOKS

OF THE NINTH GRADE OF THE ELEMENTARY SCHOOL APPROVED BY PNLD 2017

\begin{abstract}
The present work aimed to analyze and categorize the 13 science textbooks of the $9^{\text {th }}$ grade of Elementary School that were approved by PNLD 2017. This analysis seeks to understand how students are introduced to Physics in the last year of Elementary Education and how the contents are distributed in the book. The books were evaluated based four categories used in the specialized literature and Brazilian legislation. The analysis and categorization of the books revealed positive aspects, such as the fact that the amount of Physics contents is similar to that of Chemistry contents. Negative aspects included the fact that some Physics contents are not addressed or even mentioned while others are overly discussed, especially Kinematics. Since it is in Elementary School that Physics is presented and the relationship of the student with the discipline can be established, we believe that special care should be taken in the choice of textbooks, that the discussion of Mechanics Physics in the final years of Teaching Fundamental is too lengthy, and that all Physics contents such as Modern and Contemporary Physics should be covered.
\end{abstract}

Keywords: Textbooks. Elementary school. Physics teaching.

RECEBIDO EM: 31/10/2018

ACEITO EM: 8/12/2018

\footnotetext{
${ }^{1}$ Graduação em Física (2016) e Mestrado em Ensino de Ciências e Matemática (2019) pela Universidade Luterana do Brasil. Atuou como bolsista do Projeto Pibid/Capes - Programa Institucional de Iniciação à Docência entre os anos de 2014-2016. É doutoranda em Ensino de Ciências e Matemática pela Universidade Luterana do Brasil realizando pesquisas na área de STEM e ensino de Física no Ensino Fundamental.savanafreitas_@hotmail.com

${ }^{2}$ Graduação em Bacharelado em Física pela Universidade Federal de Pernambuco (1993) e Doutorado em Física pela Universidade de São Paulo (1999). Professor-adjunto da Universidade Luterana do Brasil. Tem experiência na área de Educação, em especial no Ensino de Ciências e Matemática, com ênfase em Tecnologia de Informação (TI), atuando principalmente nos seguintes temas: Investigação de Evolução Conceitual com o uso de Simulações e Modelagem Computacional, Novos Referenciais Teóricos em TI e aquisição de representações científicas por meio de TI em sala de aula. asandraden@gmail.com
} 
Ao possibilitarem a organização dos conteúdos no decorrer do período letivo, os livros didáticos são utilizados por professores como ferramentas de suporte para o processo de ensino-aprendizagem (FRISON et al., 2009). Nesse sentido, são necessárias a análise e a avaliação dos livros didáticos que chegam aos alunos, pelo fato de que é mediante esse material que é possível despertar a curiosidade e o interesse pelos estudos. Um livro didático faz parte do cotidiano escolar, sendo utilizado como "um poderoso mecanismo de seleção e de organização dos conteúdos e métodos de ensino" (SELLES; FERREIRA, 2004, p. 63). Outro fator importante a ser mencionado é que um livro didático, muitas vezes, é utilizado como o principal material instrucional dos estudantes. Em alguns casos ele é a única ferramenta usada para o ensino (MORAES, 2011).

De acordo com Garcia (2012), é importante analisar os livros didáticos em razão de estes sofrerem diversas transformações. Além disso, o autor sublinha que é preciso reconhecer que um livro didático expressa elementos da cultura escolar, e que tomar esse artefato como objeto de análise é relevante para a pesquisa em educação e ensino de modo geral.A Física, disciplina que nos interessa discutir, geralmente é apresentada aos alunos pela primeira vez no último ano do Ensino Fundamental. Em muitas escolas isso ocorre concomitantemente ao ensino de Química, dependendo da instituição e do contexto.

Conforme Milaré e Alves Filho (2010, p. 102), o ensino de Química e Física no último ano do Ensino Fundamental "é uma proposta herdada das finalidades do ensino de meados do século 20, quando até então houve, oficialmente, a predominância do modelo tradicional de ensino caracterizada pela transmissão-recepção de informações". Nosso objetivo neste trabalho foi o de descrever, por meio de uma análise quantitativa, a distribuição relativa de conteúdos específicos de Física nos diversos livros didáticos de Ciências aprovados pelo Plano Nacional do Livro Didático do triênio de 2017-2019 para uso com estudantes do nono ano do Ensino Fundamental. Acreditamos que essa análise permitirá entender, ao menos em parte, como a disciplina de Ciências apresenta os diversos conteúdos de Física desenvolvidos em aula.

Nesse contexto, para nortear a pesquisa escolhemos as seguintes perguntas-chave: Os conteúdos de Física são abordados segundo um padrão uniforme em um livro didático? Os livros didáticos de Física do nono ano do Ensino Fundamental aprovados pelo PNLD 2017 discutem a Física relacionando-a com as outras disciplinas (isto é, eles têm uma abordagem interdisciplinar)?

Concluímos nosso texto com as considerações finais a respeito do assunto e apresentamos propostas com base nos resultados obtidos.

\section{REFERENCIAL TEÓRICO}

\section{O livro didático e o ensino de Física}

De acordo com Forjan e Sliško (2014, p. 21), os livros didáticos "refletem e implementam o currículo, definem as sequências de conteúdo e explicam as leis da Física". Dito de outro modo, podemos presumir que os livros didáticos têm impacto na aprendi- 
zagem de cada estudante. No ensino da Física o papel desempenhado pelo livro didático pode ser ainda mais complexo, uma vez que a disciplina é uma ciência multifacetada, sem possibilidade de subjetividades.

Conforme Prado (2016), os livros didáticos "são utilizados há tempos nas salas de aula. Esses livros sempre tiveram o objetivo de contribuir com a metodologia de ensino dos professores, reforçando a aprendizagem em sala de aula e fora dela". As pesquisas, portanto, já esclareceram a importância da contribuição de um livro didático, especialmente no auxílio ao trabalho dos professores.

Logo, por serem indispensáveis e importantes para a educação, os livros didáticos devem ser avaliados criteriosamente. O objetivo de tal avaliação é o de assegurar a qualidade do ensino, garantindo que o livro didático se converta em uma ferramenta educacional sólida para os docentes. Por essa razão, acredita-se que o cuidado na concepção e na utilização dos livros didáticos seja essencial para que esses instrumentos mantenham sua função, concretizando os objetivos do processo de ensino-aprendizagem.

Conforme Lajolo (1996, p. 4), o livro didático "pode ser decisivo para a qualidade do aprendizado resultante das atividades escolares". Assim, é necessário adotar cautela no momento de selecionar e utilizar um livro didático de Ciências em sala de aula.Um número expressivo de pesquisas recentes mostra a falta de interesse dos estudantes pela Física (OSBORNE; SIMON; COLLINS, 2003; SALEH, 2011; CIMA; DA ROCHA FILHO; LUÍS, 2017), e acredita-se que um dos fatores que podem influenciar esse desinteresse, tanto no Ensino Fundamental quanto no Ensino Médio, é a inadequação do livro didático (REBELO et al., 2014).

Além disso, sabe-se que

O professor desempenha um papel fundamental, pois além de ser ele que está em contato direto com o aluno, é ele também que elabora e aplica a aula. E geralmente são nas aulas que muitos estudantes identificam seu foco de desinteresse pela Física. A realidade das aulas de Física, hoje em dia, não condiz com as reais necessidades e transformações do ensino na atualidade (MORAES, 2009, grifo nosso, p. 2).

Ressaltamos aqui o grifo feito por nós na citação supra: não resta dúvida de que, muitas vezes, a introdução à Física desperta no aluno a impressão de ser essa uma ciência um tanto "erudita", carente de contemporaneidade.O professor é agente fundamental na preparação e condução de uma aula; é ele que decide utilizar ou não o livro didático em suas atividades em sala de aula. Conforme D'Aquino Rosa (2017, p. 78), "a temática do uso do LD por professores na EB ainda é um campo com potencial exploração de estudos na produção acadêmica brasileira", pois são os professores que poderão adequar e retificar o livro didático conforme a necessidade.Segundo Morales, Mazzitelli e Olivera (2015), os alunos acreditam que aprender Física é difícil, porque a consideram uma ciência abstrata. Essa conclusão aponta para a necessidade de avaliar livros didáticos de Física, pois esse instrumento educacional, ressalvamos, terá efeitos positivos (ou negativos) no processo educacional dos estudantes. Pimentel (2006, p. 318) traz, ainda, que o docente "deve estar preparado para fazer uma análise crítica e julgar os méritos do livro que utiliza ou pretende utilizar, assim como para introduzir as devidas correções 
e/ou adaptações". Assim, o professor de Física deve escolher um livro didático adequado com base na necessidade de despertar nos alunos do Ensino Fundamental a paixão (por que não?) pela Física.

\section{O Plano Nacional do Livro Didático (PNLD)}

Conforme o Decreto № 9.099, de 18 de julho de 2017, o Programa Nacional do Livro Didático (PNLD) tem por objetivo fornecer às escolas públicas livros didáticos, dicionários e materiais de suporte à prática educativa. Com base nessa prerrogativa, todo livro didático usado em escolas públicas do Brasil passa por avaliação antes de ser adotado (BRASIL, 2017a). Esse esforço pela qualidade editorial objetiva garantir que conteúdos sejam apresentados e atualizados com base em uma ligação com o cotidiano dos discentes, ligação esta que despertaria o interesse dos jovens pelo estudo. Neste trabalho analisamos como esse interesse pela Física pode ser suscitado.

A avaliação dos livros didáticos para o triênio de 2017/2018/2019 teve início com o edital de Convocação 2/2015 - CGPLI -, no Diário Oficial da União de 2/2/15, seção 3, página 38 (BRASIL, 2016). Esse documento serve como base de orientação para editoras na inscrição das coleções didáticas a serem submetidas à avaliação pedagógica. O processo é realizado por universidades públicas com coordenação da Secretaria de Educação Básica (SEB/MEC).

\section{A criação de categorias com base em trabalhos anteriores}

Nos primeiros meses de 2017 buscamos artigos publicados nas plataformas de pesquisa Eric, Google Acadêmico e Scielo sobre a análise de livros didáticos de Física no Ensino Fundamental. Apesar de o universo de publicações sobre livros didáticos ser muito abrangente na área do Ensino de Física, apenas um subconjunto pequeno dessas publicações aborda a problemática de livros didáticos no Ensino Fundamental. A busca realizada encontrou 15 artigos relacionados a nossa temática, dos quais selecionamos 3 , mencionados na seção anterior, como fundamentação para a metodologia e a definição das categorias de análise. Esses artigos buscaram identificar elementos presentes nos livros didáticos capazes de explicar porque determinada obra foi selecionada. Os três artigos, dois dos quais foram publicados por autores estrangeiros, foram utilizados para nortear a criação e a elaboração das categorias-base para a análise dos livros didáticos.

O primeiro artigo, An Analysis of Science Textbooks for Grade 6: the Electric Circuit Lesson (SOTHAYAPETCH; LAVONEN; JUUTI, 2012), apresenta uma análise de livros didáticos finlandeses e tailandeses sobre circuitos elétricos usados no sexto ano. Os livros didáticos publicados nos dois países foram analisados sob quatro categorias, segundo pesquisa anterior:

Subcategorias foram definidas por indução na fase 2 do processo de pesquisa. Após a leitura preliminar (fase 2 ) foram definidas as seguintes categorias principais:Introdução de conceitos: A forma como os conceitos são introduzidos aos alunos.

Tipo de conhecimento: Texto e figuras enfatizando a aprendizagem do conhecimento procedimental ou do conhecimento conceitual. 
Representações: Toda a informação textual e pictórica nos capítulos analisados e indica que tipo de figuras, figuras ou desenhos são usados para introduzir os conceitos aos alunos.

Contextos: Conceitos no livro didático são apresentados em diferentes contextos (SOTHAYAPETCH; LAVONEN; JUUTI, 2013, p. 59. Tradução nossa).

A partir dessas categorias os autores perceberam que os livros finlandeses apresentam um número maior de conceitos e descrevem as relações entre os conceitos de circuito elétrico mais frequentemente do que os livros tailandeses. Esse fator, mencionado pelos autores, pode ser um dos motivos pelos quais os alunos finlandeses atingiram notas melhores do que os tailandeses na avaliação do Program for International Student Assessment (Pisa). Além disso, concluiu-se que os livros didáticos analisados apresentam contextos bastante tradicionais, como aplicações técnicas, contexto ideal e a tecnologia na sociedade, por exemplo.

O segundo artigo utilizado como base para a criação das categorias nesta pesquisa foi Curriculum Reform Movements and Science Textbooks: a Retrospective Examination of 6th Grade Science Textbooks (ALPASLAN; YALVAC; LOVING, 2015), o qual teve como objetivo compreender o impacto das reformas educacionais nos livros didáticos de ciências nos EUA. As categorias utilizadas no artigo citado foram: (1) os materiais utilizados; (2) a possibilidade de os conceitos de eletricidade estarem relacionados; (3) o tipo de atividade estudantil; e (4) o domínio das aprendizagens com os textos de atividades. Os autores relatam que o conceito de ensino de eletricidade, que antes envolvia o ato de "transmitir para o corpo de conhecimento e a disciplina de orientação científica", passou a incorporar "mais um aprendizado social e uma orientação pedagógica que seja centrada no aluno".

O último artigo escolhido, publicado no Brasil, foi a Análise dos conteúdos da Física nos livros didáticos de ciências das séries iniciais do Ensino Fundamental (OLIVEIRA; HOSOUME, 2009). Esse artigo analisou três coleções de livros didáticos de Ciências aprovadas pelo PNLD de 2007 para uso com as séries iniciais do Ensino Fundamental. A análise contemplou as três coleções de livros didáticos aprovadas pelo PNLD 2007 mais utilizadas em escolas estaduais e municipais na cidade de Timóteo, Estado do Mato Grosso. Para identificar os livros mais usados nessa cidade, 19 professores que ministram aulas de Ciências responderam a um questionário específico.

A primeira parte da análise dos livros didáticos teve como objetivo estabelecer a quantidade de páginas dedicadas aos seguintes conteúdos da Física: Mecânica, Acústica, Física Térmica, Óptica, Eletromagnetismo, Física Moderna e Astronomia. Esses conteúdos foram escolhidos porque são considerados tradicionais no ensino de Física na educação básica no Brasil. A segunda parte da análise apresentada no artigo foi baseada na Análise de Conteúdo de Laurence Bardin. Esta visou a identificação das dimensões conceituais, atitudinais e procedimentais relativas aos conteúdos de Física, utilizando como referência a natureza dos conteúdos especificados nos Parâmetros Curriculares Nacionais (PCNs). Empregando nessa categoria a técnica de Bardin,

[...] foi possível identificar quatro diferentes formas de desenvolvimento de temas da Física das coleções analisadas: 1 - Conceitual (C), 2 - Conceitual e Atitudinal (CA), 3 - Conceitual e Procedimental (CP), 4 - Conceitual, atitudinal e procedimental (CAP). Isso não significa que os autores das coleções tenham procurado desen- 
volver os conteúdos nessas perspectivas, mas estas categorias ou formas de desenvolvimento dão sentido aos conteúdos apresentados em termos de objetivos educacionais (OLIVEIRA; HOSOUME, 2009, p. 5).

Os PCNs sugerem que a disciplina de Ciências Naturais deve ser baseada no pressuposto de que "a compreensão dos fenômenos naturais articulados entre si e com a tecnologia confere à área de Ciências Naturais uma perspectiva interdisciplinar, pois abrange conhecimentos biológicos, físicos, químicos, sociais, culturais e tecnológicos" (BRASIL, 1998). Além disso, os PCNs enfatizam a importância de promover debates entre os professores atuantes nessa área sobre as possibilidades de desenvolver a interdisciplinaridade e a multidisciplinaridade na prática escolar.

A primeira e a segunda categorias que elaboramos - A presença da Física nos livros didáticos e A distribuição dos conteúdos de Física nos livros didáticos, respectivamente -, tiveram origem no artigo publicado no Brasil. As duas análises têm como objetivo responder à primeira pergunta de pesquisa, a qual aborda a distribuição de conteúdos de Física nesses livros didáticos e a relação entre a Física e a Química, em particular no livro didático do nono ano.

A terceira e a quarta categorias ( $A$ interdisciplinaridade nos livros didáticos e Unidades temáticas: a Terra e o Universo, matéria e energia e vida e evolução, respectivamente), foram elaboradas com base nos dois artigos internacionais, cujo objetivo foi o de analisar como eram apresentados os conceitos aos alunos e esclarecer os contextos relacionados. De maneira geral, os artigos escolhidos utilizaram categorias de análise qualitativa. No presente estudo, essas categorias foram reformuladas em categorias quantitativas, as quais investigaram a interdisciplinaridade (isto é, a existência de discussão de conceitos de Física em conjunto com outras disciplinas, exceto a Química, a qual também é ensinada no nono ano, ou a abordagem a conceitos de Física e Química apresentados em conjunto). Analisou-se, também, o uso ativo da temática BNCC para a discussão e a exposição dos conteúdos de Física.

Assim, os três trabalhos analisados formaram o alicerce para a construção da metodologia e das categorias elaboradas para a análise dos livros didáticos de Ciências no nono ano do Ensino Fundamental, aprovados pelo PNLD 2017, que já estão nas escolas públicas do país, quando são utilizados como base para o ensino e aprendizagem de Ciências.

\section{A DEFINIÇÃO DO PROBLEMA DE PESQUISA E A METODOLOGIA USADA}

Com o intuito de mostrar o caminho percorrido e a maneira como conduzimos nossa pesquisa, esta seção apresenta (1) a natureza e o tipo de pesquisa, (2) o contexto no qual foi realizada e os instrumentos utilizados de coleta de dados e (3) a metodologia de análise dos dados.

\section{1) A natureza e o tipo de pesquisa}

A abordagem de pesquisa empregada foi a análise documental. Segundo Lüdke e André (1986, p. 38), a análise documental é uma "técnica valiosa de abordagem de dados qualitativos, seja complementando as informações obtidas por outras técnicas, 
seja desvelando aspectos novos de um tema ou problema". De acordo com Lüdke e André (1986), os documentos que, em nossa pesquisa, se referem aos livros didáticos, são

[...] uma fonte poderosa de onde podem ser retiradas evidências que fundamentem afirmações e declarações do pesquisador. Representam ainda uma fonte "natural" de informação, não sendo apenas uma fonte de informação contextualizada, mas surge num determinado contexto e fornecem informações sobre esse mesmo contexto (LÜDKE; ANDRÉ, 1986, p. 39).

Dito de outra forma, acreditamos que os livros didáticos podem ser essenciais para compreender como está ocorrendo o ensino de Física no Ensino Fundamental. Conforme Caulley (apud Lüdke; André, 1986), a análise documental busca identificar informações efetivas partindo-se de questões ou hipóteses de interesse, isto é, buscando evidências que caracterizem a condução do ensino de Física no Ensino Fundamental com base em livros didáticos. Após a análise qualitativa/interpretativa, categorias foram desenvolvidas e convertidas em dados quantitativos, representados nos gráficos a seguir.

\section{2) $O$ contexto e os instrumentos de coleta de dados}

Com o objetivo de vincular o conhecimento científico ao cotidiano do aluno, os livros têm função fundamental, a qual tem reflexos na sociedade (BRASIL, 2017b). Optamos por analisar os 13 livros didáticos aprovados pelo Plano Nacional do Livro Didático no triênio 2017/2018/2019. O quadro a seguir lista os 13 livros avaliados.

Tabela 1 - Identificação dos livros do nono ano do Ensino Fundamental de Ciências

\begin{tabular}{ccc}
\hline CÓDIGO & NOME & EDITORA \\
\hline A & Investigar e Conhecer: Ciências da Natureza & Saraiva Educação \\
\hline B & Ciências da natureza. Aprendendo com o cotidiano & Moderna \\
\hline C & Projeto Teláris & Ática \\
\hline D & Projeto Araribá & Moderna \\
\hline E & Projeto Apoema & Editora do Brasil \\
\hline F & Ciências Novo Pensar & FTD \\
\hline G & Companhias das Ciências & Saraiva Educação \\
\hline H & Para Viver Juntos & SM \\
\hline I & Universos & SM \\
\hline J & Jornadas CIE & Saraiva Educação \\
\hline K & Ciências & Ática \\
\hline L & Ciências & Quinteto \\
\hline M & Tempo de Ciências & Editora do Brasil \\
\hline
\end{tabular}

Fonte: A pesquisa.

Os livros didáticos avaliados são originários de duas escolas públicas e de recursos próprios dos autores desta pesquisa. A Escola Estadual de Ensino Médio Afonso Machado Coelho, localizada na cidade de Triunfo, disponibilizou seis livros didáticos (Investigar e Conhecer: Ciências da Natureza, A; Projeto Apoema-Ciências, E; Ciências Novo Pensar, 
F; Companhias das Ciências, G; Ciências, L; e Tempo de Ciências, M). A Escola Municipal de Ensino Fundamental João Paulo I, situada na cidade de Canoas, ofereceu cinco livros didáticos (Ciências Naturais. Aprendendo com o Cotidiano, Projeto Teláris-Ciências, Projeto Araribá-Ciências, Para Viver Juntos-Ciências da Natureza e Universos-Ciências da Natureza). Os livros Jornadas CIE (Saraiva Educação) e Ciências (Editora Ática) foram comprados diretamente da Editora com recursos oriundos dos autores, pois não foram encontrados nessas escolas. Para fins de organização do trabalho, optamos por codificar cada livro com as letras maiúsculas de $\mathrm{A} M$.

\section{3) A metodologia de análise dos dados}

A metodologia utilizada na análise incluiu a obtenção dos 13 livros didáticos aprovados pelo PNLD 2017-2019. Após, determinamos quatro grandes categorias, segundo as quais os livros incluídos foram analisados: (1) a presença da Física nos livros didáticos, (2) a distribuição dos conteúdos de Física nos livros didáticos, (3) a interdisciplinaridade dos livros didáticos e (4) unidades temáticas: a Terra e o Universo, matéria e energia e vida e evolução.

A primeira categoria, chamada de a presença da Física nos livros didáticos, foi avaliada com base na contabilização do total de páginas dedicado à Física em cada obra. 0 objetivo foi o de caracterizar a real presença da Física no último ano do Ensino Fundamental.A segunda categoria, intitulada a distribuição dos conteúdos de Física nos livros didáticos, computou o número de páginas sobre os principais conteúdos de Física nos livros didáticos e os conteúdos apresentados aos alunos. Além disso, ela avaliou a ausência de algum conteúdo específico.

A categoria a interdisciplinaridade dos livros didáticos teve como objetivo descobrir se, além da Química e da Física, outras áreas da Ciências são desenvolvidas nos livros didáticos no intuito de fomentar a interdisciplinaridade, tal qual sugerem os PCNs que, futuramente, formarão a Base Nacional Comum Curricular (BNCC).A quarta categoria, unidades temáticas: a Terra e o Universo, matéria e energia e vida e evolução, teve como objetivo compreender se os livros mostram algumas características referentes ao que a BNCC definirá como base de aprendizado no decorrer das etapas e modalidades da Educação Básica.

\section{ANÁLISE E DISCUSSÃO DOS RESULTADOS}

Esta seção do artigo é dividida em cinco subseções. As quatro primeiras subseções incluem as categorias elaboradas, e a última apresenta uma breve comparação realizada com a literatura atual.

\section{A presença da Física nos livros didáticos}

A primeira categoria discutida contabilizou o total de páginas do livro didático e o número de páginas dedicadas à Física. O Gráfico 1 ilustra o espaço que a Física ocupa nos livros didáticos do nono ano do Ensino Fundamental e caracteriza as diferenças entre os livros. 


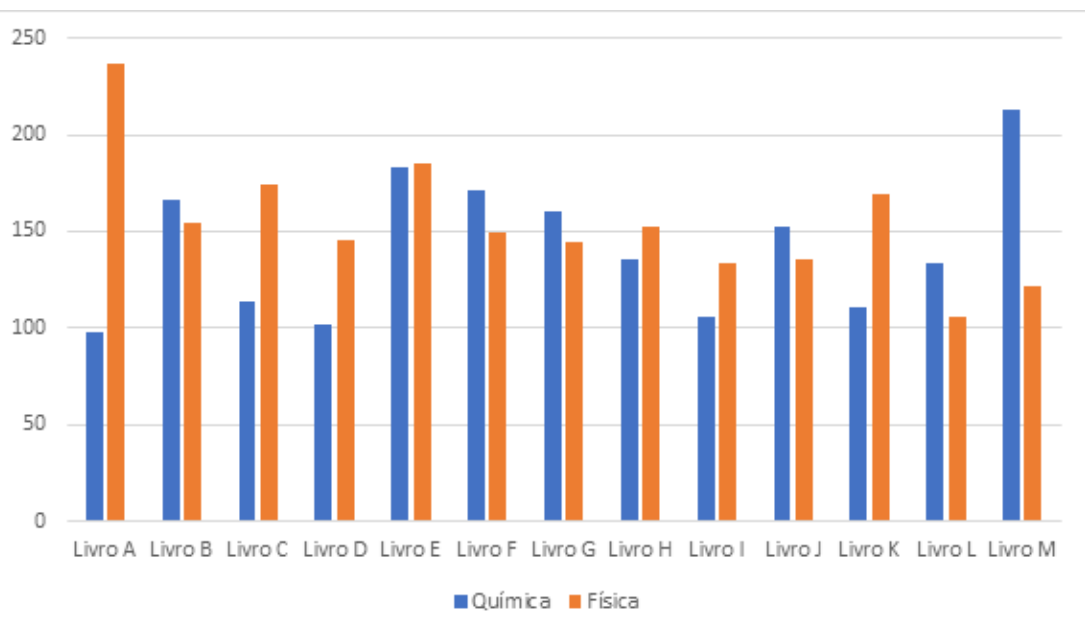

Fonte: A pesquisa.

Todos os livros aprovados pelo PNLD 2017 contemplam a Física e a Química. Dos 13 livros didáticos, em 6 o número de páginas dedicado à Física é maior do que o dedicado aos conteúdos de Química. Em 5 a situação é a inversa, com maior número de páginas destinado a conteúdos de Química. Apenas 2 livros apresentam uma distribuição uniforme entre os conteúdos de Química e Física.Conforme a análise da distribuição dos conteúdos para a série considerada, a Física pode, certamente, ser desenvolvida para os eixos (da BNCC) de universo e matéria e energia. Pressupondo que não há razão plausível para negligenciar-se a presença de Física nos livros didáticos, constatamos, felizmente, que tal imprevisão não ocorre nas obras incluídas.

A distribuição dos conteúdos de Física nos livros didáticosA segunda categoria utilizada mostra a desigualdade na distribuição dos conteúdos de Física no livro.

Nesta segunda subseção, da mesma maneira como na subseção anterior, contabilizamos as páginas para cada conteúdo de Física. Os conteúdos foram determinados após análise de todos os livros, a qual permitiu avaliar os conteúdos mais desenvolvidos nos livros didáticos. Os conteúdos encontrados foram a Física Mecânica, a Física Térmica, a Óptica, as Ondas, a Eletricidade e o Magnetismo e a Astronomia.

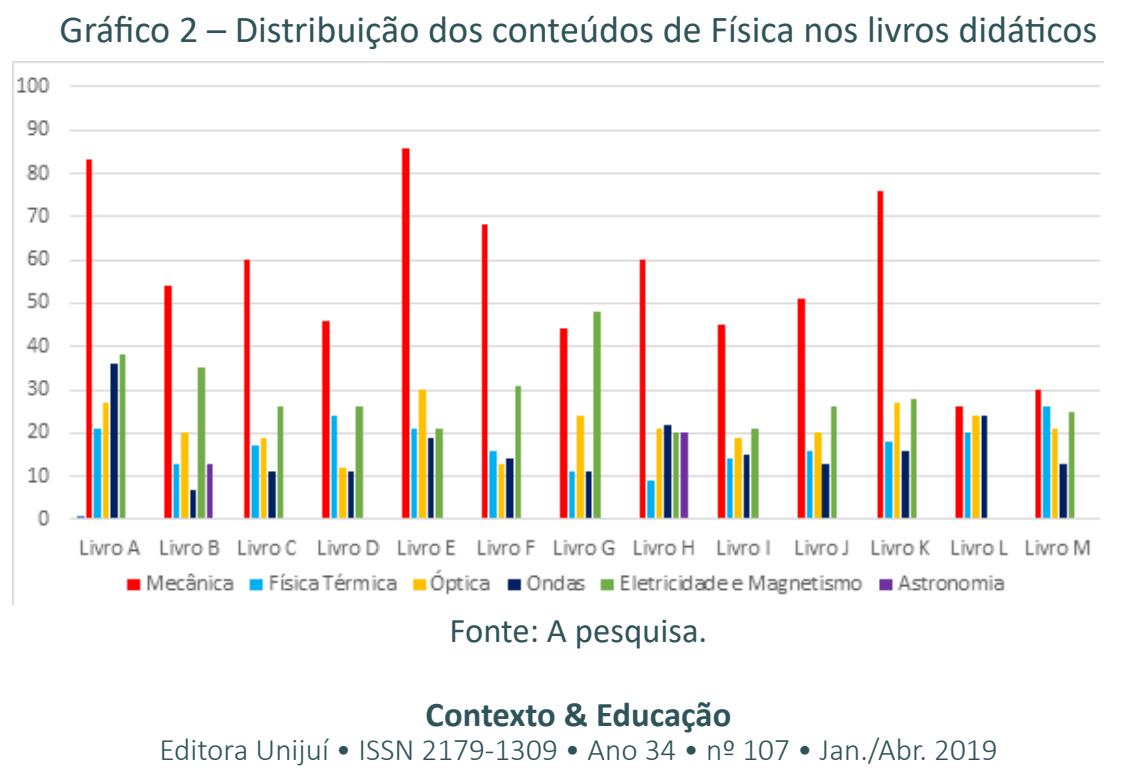


Os livros L e M têm, essencialmente, a mesma distribuição dos conteúdos de Física, como mostra o Gráfico. Física Térmica, Óptica e Ondas aparecem em todos os livros didáticos. O conteúdo sobre Astronomia é contemplado em apenas dois livros didáticos ( $\mathrm{H}$ e B).

A Física Moderna, composta pela Teoria da Relatividade e a Mecânica Quântica, não está presente em nenhum dos livros analisados. Já os conteúdos relacionados à Eletricidade e Magnetismo estão em todos os livros, exceto em um (L).Os eixos temáticos discutidos - matéria e energia - poderiam apresentar tópicos de mecânica quântica (que discutiriam propriedades fundamentais da matéria à semelhança da Química, a qual inicia a discussão pelo átomo de Bohr), enquanto o eixo universo poderia expor a Relatividade (ao discutir o universo em grande escala). Verificamos que nenhum livro tenta introduzir a Física por estes tópicos, os quais seriam capazes, talvez, de despertar mais interesse nos alunos do que a Física Mecânica.

No Gráfico 2 é possível observar como os conteúdos relacionados à Física Mecânica ocupam a maior parte do material. Este seria um dos motivos mais comuns pelos quais os alunos têm contato apenas com a Mecânica no Ensino Fundamental.

\section{A interdisciplinaridade dos livros didáticos}

Nesta categoria comparamos os livros que, além da Física e da Química, trazem os assuntos relacionados às Ciências em geral ou conteúdos que contemplam a Química e a Física abordados em capítulos separados.

Gráfico 3 - A interdisciplinaridade dos livros didáticos

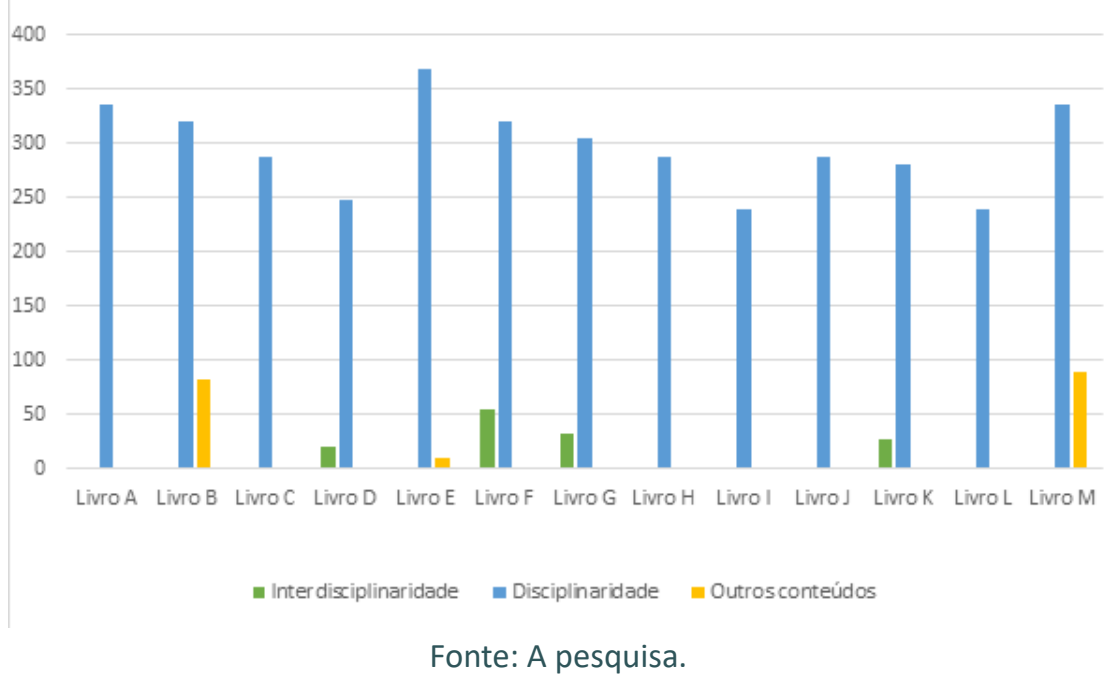

No Gráfico 3 a barra azul indica o número de páginas dedicado a uma disciplina apenas: ou à Química ou à Física. A barra verde indica a quantidade de páginas nas quais a Química e a Física são desenvolvidas em conjunto, como observado em uma explicação sobre energia e matéria, por exemplo. Por fim, a barra amarela indica o quanto do livro aborda outros assuntos de Ciências, como genética e Ciência, Tecnologia e Sociedade (CTS). 
Os livros que trazem essa categoria (a interdisciplinaridade nos livros didáticos) foram B, D, E, F, G, K e M.O livro B traz diversos assuntos de Ciências, como vida e ambiente, que tratam da evolução da diversidade, da reprodução de seres vivos e da variabilidade dos descendentes. Em outro capítulo a obra cobre ser humano e saúde com base em temas como a reprodução humana e as responsabilidades associadas. A obra também tem um capítulo sobre como funciona a genética nos seres humanos.

O livro D oferece algumas páginas sobre as propriedades da matéria, contemplando tanto a Química quanto a Física por meio dos estados e mudanças de estado físico da matéria.

O livro E separa Química e Física em duas unidades distintas, mas antes dedica 12 páginas à CTS, trazendo assuntos do cotidiano dos estudantes.

O livro $F$, assim como o livro $E$, separa em duas unidades diferentes a Química e a Física. O começo do livro, porém, traz uma unidade dedicada ao estudo da Matéria e Energia, introduzindo noções básicas da Química e da Física. O livro G também separa claramente a Química e a Física e começa com uma unidade sobre os fundamentos da Química e da Física, abordando assuntos como matéria, energia e transformações da matéria e da energia.O último livro que citamos nessa categoria (M) não faz separação entre Química e Física, mas traz conteúdos como CTS, sustentabilidade, hereditariedade e sexualidade, os quais foram contemplados de outras maneiras nos demais livros didáticos avaliados.É importante lembrar que dos conteúdos de Química desenvolvidos destaca-se a estrutura atômica e o átomo de Bohr, tópico este considerado fundamental para o estudo de Física Atômica e Molecular em nível introdutório. Nenhum destes livros tentou desenvolver conteúdos de Física e Química concomitantemente à discussão deste tópico.

\section{Unidades temáticas: matéria e energia, vida e evolução e a Terra e o Universo}

A Base Nacional Comum Curricular (BNCC), que será efetivada a partir de 2019, é um documento "normativo que define o conjunto orgânico e progressivo de aprendizagens essenciais que todos os alunos devem desenvolver ao longo das etapas e modalidades da educação básica" (BRASIL, 2017b). Ela tem como principal objetivo oferecer aos alunos uma formação integral mediante o desenvolvimento das chamadas competências do século 21.Esse documento é embasado na Constituição de 1988, artigo 205, o qual reconhece a educação como um direito fundamental que deve ser compartilhado entre Estado, família e sociedade. A educação é "direito de todos e dever do Estado e da família, será promovida e incentivada com a colaboração da sociedade" (BRASIL, 1988). Em seu artigo 210, a Carta Constitucional cita a importância de conteúdos "mínimos" no Ensino Fundamental, os quais respeitem os valores culturais e artísticos em âmbito nacional e regional no Brasil (BRASIL, 1988). De acordo com Rodrigues e Groenwald (2017), $60 \%$ da BNCC representam os conteúdos mínimos que devem ser desenvolvidos em sala de aula; os demais $40 \%$ ficam a critério do sistema educacional de cada estado do Brasil. Os conteúdos sugeridos para o nono ano do Ensino Fundamental, os quais se inserem em nosso objetivo neste artigo, abordam três unidades temáticas a serem trabalhadas, sendo elas matéria e energia, vida e evolução e a Terra e o Universo. 
A primeira área temática tem como objeto de conhecimento o desenvolvimento de aspectos quantitativos das transformações Químicas, a estrutura da matéria e as radiações e suas aplicações na saúde. A segunda área temática - vida e evolução - visa a desenvolver com os alunos o conhecimento sobre hereditariedade, ideias evolucionistas e a preservação da biodiversidade. Por fim, a última área temática tem como objeto de conhecimento a composição, a estrutura e a localização do Sistema Solar no Universo, a Astronomia e a cultura, a vida humana fora da Terra, a ordem de grandeza astronômica e a evolução estelar.

Contabilizamos as páginas que continham os conteúdos relacionados a essa temática. Nosso único objetivo nessa categoria foi o de elucidar se os livros didáticos trazem alguns conteúdos referentes ao que é sugerido pela BNCC. Esse conhecimento permitiria uma discussão dos conteúdos de Física e Química com foco na interdisciplinaridade.

Conforme o Gráfico 4, todos os livros didáticos têm páginas destinadas à matéria e energia (aspectos quantitativos das transformações químicas, estrutura da matéria, características da radiação eletromagnética e aplicações na saúde).

Em relação à vida e evolução (hereditariedade, ideias evolucionistas, preservação da biodiversidade), apenas três livros desenvolvem esses conteúdos. 0 item $a$ Terra e $o$ Universo (composição, estrutura e localização do sistema solar no universo, astronomia e cultura, vida humana fora da Terra, ordem de grandeza astronômica, evolução estelar) está presente em quatro livros, mas em pouquíssimas páginas, sem a devida abordagem.

O último item - Outros - é destinado aos demais conteúdos que não se encaixam em nenhuma das três unidades temáticas, seus objetivos e habilidades conforme a BNCC.

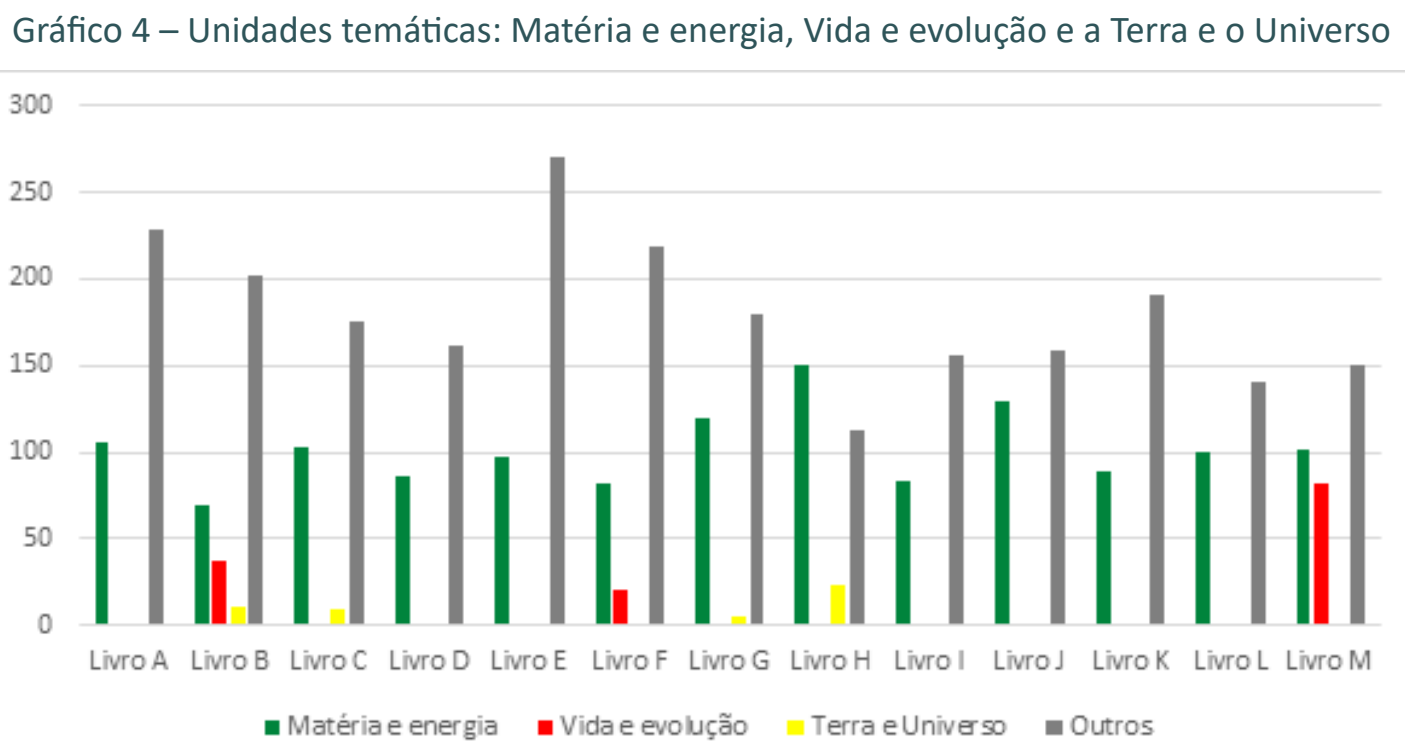

Diante desses Gráficos é notável que, assim como observam Oliveira e Hosoume (2009) em sua pesquisa, todas as áreas da Física são contempladas nos livros didáticos, menos a Física Moderna e Contemporânea. Os autores retratam, ainda, que apenas um livro tem uma distribuição baixa de conteúdos de Física. Na presente pesquisa observou-se representação semelhante. Dois livros têm distribuição equivalente; dos demais, em seis prevalecem os conteúdos de Química, e em cinco a Física ocupa maior número de páginas. 
As pesquisas realizadas por Alpaslan (2015) e Sothayapetch, Lavonen e Juuti (2013) foram nossa inspiração para a elaboração das duas últimas categorias de análise. A primeira teve o intuito de comparar os livros didáticos publicados de 1975 a 1997 em relação aos capítulos relacionados com eletricidade; a segunda teve o objetivo de comparar os livros tailandeses e finlandeses.

A comparação e análise utilizadas pelos pesquisadores nos permitiram observar se existe interdisciplinaridade nos livros didáticos, posto que a legislação brasileira sugere a abordagem interdisciplinar. Além disso, foi possível analisar se os livros estão no caminho sugerido pela BNCC, documento que tem o objetivo de nortear a elaboração dos currículos em todo o Brasil.

A interdisciplinaridade, infelizmente, ainda não é abordada em todos os livros, mas muitos já trabalham com o assunto Energia e Matéria ou CTS de forma a abordar a Química e a Física. A categoria unidades temáticas mostra que alguns livros já estão desenvolvendo assuntos sugeridos pela BNCC.Em vista do que foi discutido, ao confrontarmos os dados que obtivemos com os três referenciais teóricos adotados na criação das categorias usadas, observa-se que as duas primeiras categorias (a presença da Física nos livros didáticos e a distribuição dos conteúdos nos livros didáticos, elaboradas com base na pesquisa de Oliveira e Hosoume (2009), alcançaram dados semelhantes, embora as coleções analisadas tenham sido publicadas em um intervalo de dez anos. As duas últimas categorias relacionadas após a leitura do artigo dos autores, confirmam que, por mais que se indique o trabalho interdisciplinar na disciplina de Ciências, ele ainda não é contemplado nos livros didáticos como deveria.

\section{CONSIDERAÇÕES FINAIS}

Diante dos resultados adquiridos neste trabalho, cujo intuito foi o de descrever, por meio de uma análise quantitativa, a distribuição relativa de conteúdos específicos de Física nos diversos livros didáticos de Ciências, foi possível identificar, primeiramente, que quase todos os livros contemplam as áreas de Física e Química equivalentemente. Além disso, praticamente todos os conteúdos de Física são abordados, exceto a Física Moderna e Contemporânea. Já a interdisciplinaridade não é contemplada na maioria dos livros didáticos, nos quais a Química e a Física são tratadas separadamente; poucos livros têm um capítulo retratando Energia e Matéria ou CTS como base interdisciplinar.

É possível afirmar que algumas modificações aperfeiçoariam os próximos livros didáticos de Ciências usados no nono ano do Ensino Fundamental. A quantidade de conteúdos de Física Mecânica (estudo dos movimentos dos corpos) pode ser reduzida, uma vez que esse tema é abordado em proporção maior do que os demais. Se esta redução for instituída, será possível abordar todos os conteúdos de Física e, em especial, a Física Moderna e Contemporânea, a qual não é abordada em nenhum livro didático.

A interdisciplinaridade é um fator importantíssimo para o estudo de Ciências, pois integra diversas áreas do conhecimento. O principal foco deste trabalho foi de investigar e analisar de que maneira a Física e a Química são contempladas nos livros didáticos de Ciências do nono ano do Ensino Fundamental. Logo, após a investigação e análise dos 
livros didáticos, acreditamos que seja necessário que os livros abordem a Física e a Química e, talvez, a Biologia, conjuntamente, considerando que as três disciplinas possuem caráter científico.

A BNCC determinará o que as escolas precisarão elaborar em seus currículos. Segundo a BNCC, todos os estudantes do Brasil desenvolverão, ao longo das etapas e modalidades da Educação Básica, um conjunto orgânico e progressivo de aprendizagens primordiais. Assim, é necessário que os livros acompanhem o que sugere a BNCC para que tal objetivo seja alcançado. Conforme os resultados, é notável que alguns livros já abordem as temáticas sugeridas pela BNCC, como Matéria e Energia.

Conclui-se que os livros didáticos são os principais agentes influenciadores do currículo, servindo de orientação para a definição dos conteúdos e das atividades a serem ministrados pelos docentes. Acreditamos que o livro didático é o material mais utilizado pelo professor de Física e que, muitas vezes, talvez ele seja a única ferramenta didática disponível. É preciso, contudo, ter cuidado com a elaboração dos livros didáticos, viabilizando aos alunos a oportunidade de ter contato com todos ou, pelo menos, os principais conteúdos de Física no Ensino Fundamental, o que lhes permitirá chegar ao Ensino Médio com uma imagem mais realista do que é a Física.

\section{REFERÊNCIAS}

ALPASLAN, M. M.; YALVAC, B.; LOVING, C. C. Curriculum Reform Movements and Science Textbooks: a Retrospective Examination of 6th Grade Science Textbooks. Eurasia Journal of Mathematics, Science \& Technology Education, v. 11, n. 2, p. 207-216, mar. 2015. ISSN: 1305-8215. Disponível em: http://www.ejmste. com/Issue-2-2015,1090. Acesso em: 22 maio 2018. DOI: https://doi.org/10.12973/eurasia.2015.1362a.

ASLAN, O. How do Turkish Middle School Science Coursebooks Present the Science Process Skills? International Journal of Environmental and Science Education, v. 10, n. 6, p. 829-843, 2015. ISSN: 13063065. Disponível em: https://files.eric.ed.gov/fulltext/EJ1082094.pdf. Acesso em: 22 maio 2018. DOI: 10.12973/ ijese.2015.279a.

BRASIL. Decreto № 9.099, de 18 de julho de 2017a. Disponível em: http://www.planalto.gov.br/ccivil_03/_ato2015-2018/2017/decreto/D9099.htm. Acesso em: 3 jun. 2018.

BRASIL. Ministério da Educação. Base Nacional Comum Curricular. Brasília, DF, 2017b. Disponível em: http://basenacionalcomum.mec.gov.br/. Acesso em: 13 abr. 2018.

BRASIL. Ministério da Educação. PNLD 2017: ciências - Ensino Fundamental, Anos Finais. Brasília, DF: Ministério da Educação; Secretaria de Educação Básica; Fundo Nacional de Desenvolvimento da Educação, 2016. Disponível em: http://www.fnde.gov.br/pnld-2017/. Acesso: 22 maio 2018.

BRASIL. Parâmetros Curriculares Nacionais (PCNs). Ciências Naturais. Brasília: MEC; SEF, 1998. Disponível em: http://portal.mec.gov.br/seb/arquivos/pdf/ciencias.pdf. Acesso em: 22 maio 2018.

BRASIL. Constituição Federal de 1988. Artigos 205 e 210.

CHOPPIN, A. História dos livros e das edições didáticas: sobre o estado da arte. Educação e Pesquisa, v. 30, n. 3, p. 549-566, 2004. ISSN 1678-4634. Disponível em: http://www.scielo.br/pdf/ep/v30n3/a12v30n3. pdf. Acesso em: 22 maio 2018. DOI: http://dx.doi.org/10.1590/S1517-97022004000300012.

CIMA, R. C.; DA ROCHA FILHO, J. B.; LUÍS, J. Redução do interesse pela física na transição do Ensino Fundamental para o Ensino Médio: a perspectiva da supervisão escolar sobre o desempenho dos professores. Revista Electrónica de Enseñanza de las Ciencias, v. 16, n. 2, p. 385-409, 2017. ISSN 1579-1513. Disponível em: http://reec.uvigo.es/volumenes/volumen16/REEC_16_2_11_ex1088.pdf. Acesso em: 22 maio 2018.

D'AQUINO ROSA, M. O uso do livro didático de ciências na educação básica: uma revisão dos trabalhos publicados. Revista Contexto \& Educação, [S.I.], v. 32, n. 103, p. 55-86, dez. 2017. ISSN 2179-1309. Disponível em: https://www.revistas.unijui.edu.br/index.php/contextoeducacao/article/view/6787. Acesso em: 22 maio 2018. DOI: https://doi.org/10.21527/2179-1309.2017.103.55-86.

FORJAN, M.; SLIŠKO, J. Simplifications and Idealizations in High School Physics in Mechanics: a Study of Slovenian Curriculum and Textbooks. European Journal of Physics Education, v. 5, n. 3, 2014. ISSN 13097202. Disponível em: https://files.eric.ed.gov/fulltext/EJ1051489.pdf. Acesso em: 22 maio 2018. 
FRISON, M. D. et al. Livro didático como instrumento de apoio para construção de propostas de ensino de ciências naturais. In: ENCONTRO NACIONAL DE PESQUISA EM EDUCAÇÃO DE CIÊNCIAS, 7., 2009, Florianópolis. Anais [...]. Florianópolis, SC. 2009.

GARCIA, N. M. D. Livro didático de física e de ciências: contribuições das pesquisas para a transformação do ensino. Educar em Revista, Curitiba, Brasil: ,n. 44, p. 145-163, abr./jun. 2012. ISSN 1984-0411. Disponível em: http://www.scielo.br/pdf/er/n44/n44a10.pdf. Acesso em: 15 maio 2018.

LAJOLO, M. Livro didático: um (quase) manual de usuário. Em aberto, v. 16, n. 69, p. 3-9, jan.-mar. 1996. ISSN 2176-6673. Disponível em: http://emaberto.inep.gov.br/index.php/emaberto/article/ view/2061/2030. Acesso em: 22 maio 2018. LÜDKE, M.; ANDRÉ, M. E. D. A. Pesquisa em educação: abordagens qualitativas. São Paulo: EPU, 1986.

MILARÉ, T.; ALVES FILHO, J. P. Ciências no nono ano do Ensino Fundamental: da disciplinaridade à alfabetização científica e tecnológica. Ensaio Pesquisa em Educação em Ciências, v. 12, n. 2, p. 102-120, 2010. ISSN 1983-2117. Disponível em: https://seer.ufmg.br/index.php/ensaio/article/view/8601/6540. Acesso em:22 maio 2018.

MORAES, J. U. P. A visão dos alunos sobre o ensino de Física: um estudo de caso. Scientia Plena, v. 5, n. 11, 2009. ISSN 1808-2793. Disponível em: https://www.scientiaplena.org.br/sp/article/view/736/392. Acesso em: 22 maio 2018.

MORAES, J. U. P. O livro didático de física e o ensino de física: suas relações e origens. Scientia Plena, v. 7, n. 9, 2011. ISSN 1808-2793. Disponível em: https://www.scientiaplena.org.br/sp/article/view/385. Acesso em: 22 maio 2018.

MORALES, L. M.; MAZZITELLI, C. A.; OLIVERA, A. C. La enseñanza y el aprendizaje de la Física y de la Química en el nivel secundario desde la opinión de estudiantes. Revista electrónica de investigación en educación en ciencias, v. 10, n. 2, p. 11-19, dez. 2015. ISSN 1850-6666. Disponível em: http://ppct.caicyt.gov. ar/index.php/reiec/article/viewFile/7766/6958. Acesso em: 22 maio 2018.

OLIVEIRA, E. A. G.; HOSOUME, Y. Análise dos conteúdos da Física nos livros didáticos de ciências das séries iniciais do Ensino Fundamental. In: ENCONTRO NACIONAL DE PESQUISA EM EDUCAÇÃO EM CIÊNCIAS - ENPEC, 7., e ENCONTRO DE PESQUISA EM EDUCAÇÃO EM CIÊNCIAS - ENPEC, 11., 2009, Florianópolis. Anais [...]. Florianópolis, 2009.

OSBORNE, J.; SIMON, S.; COLLINS, S. Attitudes Towards Science: a Review of the Literature and Its Implications. International Journal of Science Education, v. 25, n. 9, p. 1.049-1.079, nov. 2003. ISSN 0950-0693. Disponível em: https://www.tandfonline.com/doi/abs/10.1080/0950069032000032199. Acesso em: 22 maio 2018. DOI: https://doi.org/10.1080/0950069032000032199

PIMENTEL, J. R. Livros didáticos de ciências: a física e alguns problemas. Caderno Brasileiro de Ensino de Física, v. 15, n. 3, p. 308-318, ago. 2006. ISSN 2175-7941. Disponível em: https://periodicos.ufsc.br/index. php/fisica/article/view/6889>.Acesso em: 22 maio 2018. DOI: https://doi.org/10.5007/\%25x

PRADO, Eliane Mimesse. As práticas pedagógicas dos professores da educação básica na interação com os livros didáticos digitais. Revista Contexto \& Educação, [S.I.], v. 31, n. 98, p. 111-132, nov. 2016. ISSN 2179-1309. Disponível em: https://www.revistas.unijui.edu.br/index.php/contextoeducacao/article/ view/5480. Acesso em: 8 out. 2018. DOI: https://doi.org/10.21527/2179-1309.2016.98.111-132.

REBELO, W. R. X. et al. A qualidade e o uso do livro didático por professores de física do Ensino Médio. Latin American Journal of Science Education, v. 1, n. 22.029, p. 1-8, 2014. ISSN 2007-9842. Disponível em: www.lajse.org/nov14/22029_Rebelo.pdf. Acesso em: 22 maio 2018.

RODRIGUES, G. S.; GROENWALD, C. L. O. BNCC: concepções de professores de matemática dos anos Finais do Ensino Fundamental do município de canoas. In: CONGRESSO INTERNACIONAL DE ENSINO DA MATEMÁTICA - CIEM, 7., 2017, Canoas-RS. Anais [...].Canoas, 2017.

SALEH, S. The Effectiveness of Brain-Based Teaching Approach in Dealing With the Problems of Students' Conceptual Understanding and Learning Motivation Towards Physics. Educational Studies, v. 38, n. 1, p. 19-29, maio 2011. ISSN 0013-1954. Disponível em: https://www.tandfonline.com/doi/abs/10.1080/0305 5698.2011.570004. Acesso em: 22 maio 2018. DOI: https://doi.org/10.1080/03055698.2011.570004

SELLES, S. E.; FERREIRA, M. S. Influências histórico-culturais nas representações sobre as estações do ano em livros didáticos de ciências. Ciência \& Educação, Bauru, v. 10, n. 1, p. 101-110, 2004. ISSN 1980-850X. Disponível em: http://www.scielo.br/pdf/ciedu/v10n1/07.pdf. Acesso em: 22 maio 2018. DOI: http://dx. doi.org/10.1590/S1516-73132004000100007

SOTHAYAPETCH, P.; LAVONEN, J.; JUUTI, K. An Analysis of Science Textbooks for Grade 6: the Electric Circuit Lesson. Eurasia Journal of Mathematics, Science \& Technology Education, v. 9, n. 1, p. 59-72, 2012. ISSN 1305-8223. Disponível em: http://www.ejmste.com/An-Analysis-of-Science-Textbooks-nfor-Grade-6-The-Electric-Circuit-nLesson,74785,0,2.html. Acesso em: 22 maio 2018. DOI: https://doi.org/10.12973/ eurasia.2013.916a 